\title{
Eco-Ethics International Union: Present status and co-operation among Chapters
}

\author{
Otto Kinne* \\ EEIU President, Headquarters, Nordbuente 28, 21385 Oldendorf/Luhe, Germany
}

The Eco-Ethics International Union (EEIU) grows at an amazing rate. It continues to receive much worldwide attention, applause and support. More and more people realise that the Union's concepts and theses as formulated in our EEIU Brochures (Kinne 2004) now available in 10 languages (see www.eeiu.org/ eeiubrochure.html) - hold important keys for a better understanding of the enormous difficulties that confront modern humanity, and provide solutions for addressing and solving many of the ecological problems that increasingly burden our societies (see also Cairns 2002, 2003).

The EEIU presently operates in 73 countries and comprises 86 Chapters in all parts of the globe. The Union enjoys support from 95 EEIU Fellows and 1154 EEIU Members. For details please consult www.eeiu.org/members.html.

EEIU Chapters are local components that represent the Union in areas often characterised by different historical backgrounds, cultures and religions. Union Chapters are allowed a considerable degree of independence. In this way they can respond and adjust to local conditions and requirements. The variety of our Chapters provides examples of how local diversity can be embedded in global unity (Kinne 2003).

EEIU Headquarters and General Office are receiving growing numbers of applications from people who intend to form new Chapters. New Chapters and their Chairs are instituted by the Union Presidency (President or Vice President). In order to all ow sufficient periods of time for organising and developing their Chapters, appointed Chairs are not limited in their terms of office.

Succeeding Chapter Chairs are elected by the M embers of their Chapters. Such abiding by democratic principles guarantees perpetuated rejuvenation. The office term for an elected Chair is 5 years. Re-election is possible.

The degree of independence granted to each Chapter includes the possibility of organising patterns of cooperation among Chapters within a given country. Such national Chapter co-operation can

- strengthen the relations with governmental and non-governmental organisations

- increase the chances for obtaining financial funds and other kinds of support

- enlarge the overall significance of the Union.

Formalised Chapter co-operation in a given country requires convincing common concepts, co-ordination of plans and actions, as well as the written consent of all Chapter Chairs involved. It also requires a green light from the EEIU Presidency.

Super-Chapter Officials must be democratically elected by all Chairs of co-operating Chapters. The term of Super-Chapter Officials is 5 years. The Officials may be re-elected.

\section{LITERATURE CITED}

Cairns J J r (2002) Goals and conditions for a sustainable world. ESEP Book 1. Available at www.esep.de/journals/esep/esepbooks/CairnsEsepBook.pdf

Cairns J J r (2003) Eco-ethics and sustainability ethics. ESEP Book 2, Part 1. Available at www.esep.de/journals/esep/ esepbooks/EB2Pt1.pdf

Kinne O (2003) EEIU: Local diversity embedded in global unity. ESEP 2003:81, available at www.esep.de/articles/ esep/2003/E39.pdf

Kinne O (2003) EEIU Brochure. English original. InterResearch, Oldendorf/Luhe 